\title{
A theoretical strategy for acceleration of human immune response against SARS-CoV-2: a fusion protein harboring virus-binding and pre-exposed antigen domains
}

\author{
Reza Rahmani $^{1} \cdot$ Neda Eivazi $^{1} \cdot$ Maliheh Paknejad $^{1} \cdot$ Mahdi Aminian $^{1,2}$
}

Received: 3 October 2020/ Accepted: 3 June 2021 / Published online: 13 July 2021

(C) Indian Virological Society 2021

\begin{abstract}
Coronavirus disease 2019 (COVID-19) is a respiratory disease that outbreaks since December 2019 and spread globally. Various methods have been used to treat SARS-CoV-2 that is generally based on the information obtained from the therapeutic approaches used for SARSCOV and MERS patients. In this article, we introduce a theoretical strategy in which a two-domain fusion protein presents the virus to the immune system. This fusion protein contains a viral-binding domain such as the ACE2 domain and a domain such as the hepatitis B antigen that has previously been exposed to the immune system. This two-domain fusion protein, could be called "virus-presenting fusion protein", would attach to the virus spike protein via the ACE2 domain while the hepatitis B antigen would be bound by anti-hepatitis B antibodies facilitating the opsonization and presentation of the virus to the immune system. We believe that this virus-presenting fusion protein will accelerate the immune response to the SARS-CoV-2 virus.
\end{abstract}

Keywords COVID-19 - SARS-CoV-2 - Fusion Protein . Spike-binding domains $\cdot$ Pre-exposed antigen

Mahdi Aminian

Amminian@tums.ac.ir

1 Department of Clinical Biochemistry, School of Medicine, Tehran University of Medical Sciences, Tehran, Iran

2 Recombinant Vaccine Research Center, Tehran University of Medical Sciences, Tehran, Iran

\section{Introduction}

Coronavirus disease 2019 (COVID-19) began as an outbreak in Wuhan city, China in December 2019 and since then has spread globally. COVID-19 is caused by the severe acute respiratory syndrome coronavirus 2 (SARS$\mathrm{CoV}-2$ ) belongs to the Coronvirinae subfamily, in the Coronaviridae family of the Nidovirales order [21]. There are two diseases similar to COVID-19 over the last two decades, the severe acute respiratory syndrome coronavirus (SARS-CoV) that caused an epidemic with a $10 \%$ fatality in 2002-2003, and the Middle East respiratory syndrome coronavirus (MERS-CoV) that caused an epidemic with a $37 \%$ fatality rate in 2012 [19]. Genomic analysis revealed that SARS-CoV-2 shares $79.5 \%$ and $50 \%$ similarity to the SARS-CoV and MERS-CoV, respectively [28].

The outer surface of SARS-CoV-2 is covered with a spike protein, which contains two subunits, S1 and S2 [22]. The S1 subunit contains the receptor-binding domain (RBD) that binds to angiotensin-converting enzyme-2 (ACE2) receptor on cells in the lungs and some other organs while the S2 subunit causes cell fusion [2, 16]. What is different between SARS-CoV and SARS-CoV-2 pathogenesis is much greater affinity of SARS-CoV-2 to bind ACE-2 [27]. RBD of SARS-CoV-2 possesses a single mutation that leads to enhancement of binding to ACE2, leading to high prevalence of infections [24].

Various methods have been used to treat SARS-CoV-2 patients that are generally based on the information obtained from the therapeutic approaches used for SARS$\mathrm{CoV}$ and MERS. These methods that are in development are summarized here [24]. The first, including RNA-dependent RNA polymerase inhibitors use such as favipiravir, ribavirin and remdesivir $[3,5,25]$. As well viral protease inhibitors like lopinavir/ritonavir and darunavir 
[13]. Viral entry inhibitors for example hydroxychloroquine, ivermectin and camostat mesylate that targets the TMPRSS2 protease and prevents ACE2 cleavage that augments the entry of SARS-CoV-2 into cells are other items $[6,25,25]$. And also monoclonal antibodies such as sarilumab and tocilizumab [12]. Nutritional supplements can also be mentioned like vitamin $\mathrm{D}$ and folic acid $[10,14]$. Some items do not fall into a specific category for example methylprednisolone and colchicine [7, 17]. Utilization of plasma of convalescent patients is another method to defense new patients against SARS-CoV-2 because of a possible neutralizing specific antibody response [18, 20]. Additionally, inhibition of S-protein binding to the targets has been applied by using a soluble RBD or specific antibodies against ACE2 [15]. Human recombinant soluble ACE2 (hrsACE2) has been suggested to reduce the symptoms of COVID-19 [23].

\section{A theoretical virus-presenting fusion protein}

By this idea, we would introduce a strategy in which a twodomain fusion protein facilitates the presentation of the virus to the immune system. This fusion protein contains a virus- binding domain and an immune system pre-exposed antigen counterpart. This two-domain fusion protein, which can be called "virus-presenting fusion protein", could attach to the virus spike protein and present the virus to the immune system by binding antibodies to the pre-exposed antigen (Fig. 1). In fact, the immune system's response to the virus is accelerated by detection of pre-exposed antigen that has been added to the fusion protein. And also this response leads to elimination of fusion protein along with what it carries (SARS-CoV-2). In the following, some of the candidate proteins for each part of this two-domain fusion protein are described.

\section{Spike-binding domains}

Angiotensin converting enzyme 2 (ACE2) is a protein abundantly on the apical surface of airway epithelial and other cells. ACE2 is the receptor for SARS-CoV-2 and serves as the cellular entry point for this virus [16]. The SARS-CoV-2 spike protein binds to ACE2 with high affinity and therefore, the recombinant ACE2 can be used as the suggested virus-presenting fusion protein. Transmembrane region of ACE2 can be suggested as a

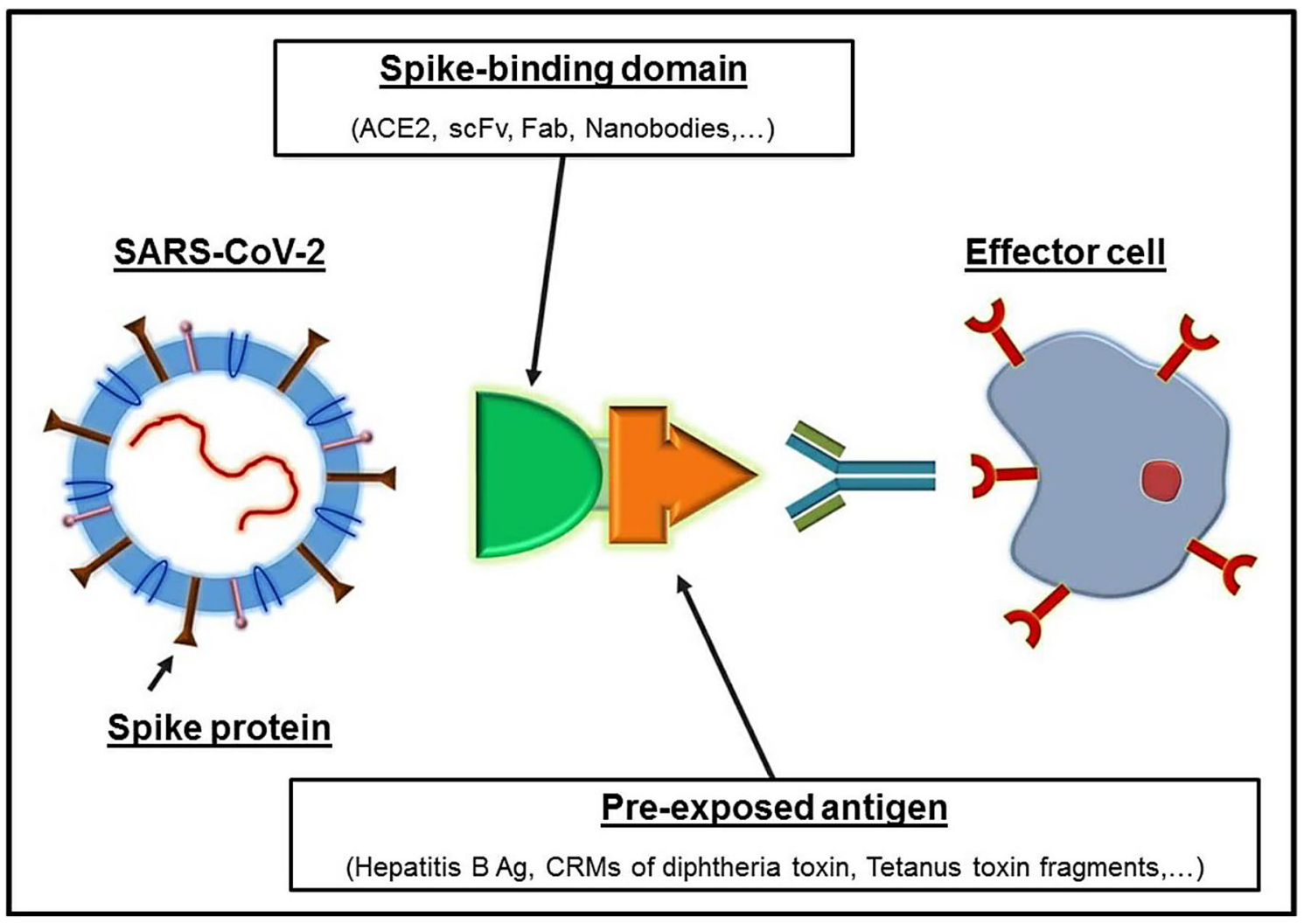

Fig. 1 Two-domain virus-presenting fusion protein: Spike-binding domain of the fusion protein attaches to the SARS-CoV-2 and facilitate the virus presenting to the immune system using pre-exposed antigen domain 
suitable sequence to replace by the pre-exposed antigen counterpart.

Other items that can be used as spike-binding domain are recombinant antibodies (rAbs) which are small recombinant fragments containing variable regions of heavy and light chains of whole antibodies [26]. These recombinant antibodies bind to a single epitope, indicating their high specificity [11]. Single chain variable fragment (scFv), fragment antigen-binding ( $\mathrm{Fab}$ ), and single-domain antibody ( $\mathrm{sdAb}$ ) are several $\mathrm{rAb}$ formats that could be selected by in vitro biopanning of different phage libraries against recombinant spike protein of SARS-CoV-2 [4, 8]. The ACE2 or one of these spike-binding recombinant antibodies can be encoded in a single gene cassette along with the immune system pre-exposed antigen to express a two-domain virus-presenting fusion protein.

\section{Pre-exposed antigens}

Pre-exposed antigens described here are proteins that already have been known by the immune system from previous vaccinations. The monovalent antigens presented in WHO recommended vaccines are suitable for this purpose which the high percentage of worldwide people have been vaccinated against them. Hepatitis B antigen (HBSAg), cross-reacting materials (CRMs) of diphtheria toxin (DT), and also recombinant fragments of tetanus toxins (TT) are monovalent antigens which could be fused to the virus-binding domain counterpart using genetic engineering approaches.

\section{Conclusion}

In conclusion, although the idea for producing a two-domain virus-presenting fusion protein has not yet been practiced against SARS-CoV-2 virus, this idea would have a potential propensity to elicit an accelerated immune response against SARS-CoV-2 immediately after injection of this recombinant fusion protein. In addition, it could be used alongside with the future anti-COVID vaccine to make sure protectivity against SARS-CoV-2 during the time required for effective activation of the immune system by the vaccine. We hope that this idea, along with the other efforts, could help the universal combat against SARSCoV-2 and any other emerging viruses and infections.

\section{References}

1. Ahmad ZA, Yeap SK, Ali AM, Ho WY, Alitheen NBM, Hamid M. scFv antibody: principles and clinical application. Clin Dev Immunol. 2012;2012:1-15.

2. Belouzard S, Chu VC, Whittaker GR. Activation of the SARS coronavirus spike protein via sequential proteolytic cleavage at two distinct sites. Proc Natl Acad Sci. 2009;106(14):5871-6.

3. Chilamakuri R, Agarwal S. COVID-19: characteristics and Therapeutics. Cells. 2021;10(2):206.

4. Colcher D, Pavlinkova G, Beresford G, Booth B. Pharmacokinetics and biodistribution of genetically-engineered antibodies. Q J Nucl Med Mol Imaging. 1998;42(4):225.

5. Dabbous HM, Abd-Elsalam S, El-Sayed MH, Sherief AF, Ebeid FF, Abd El Ghafar MS, Soliman S, Elbahnasawy M, Badawi R, Tageldin MA. Efficacy of favipiravir in COVID-19 treatment: a multi-center randomized study. Archiv Virol. 2021; 166(3):949-54.

6. Dallocchio R, Dessì A, De Vito A, Delogu G, Serra P, Madeddu G. Early combination treatment with existing HIV antivirals: an effective treatment for COVID-19? Eur Rev Med Pharmacol Sci. 2021;25(5):2435-48.

7. Espinola MSB, Bertelli M, Bizzarri M, Unfer V, Laganà AS, Visconti B, Aragona C. Inositol and vitamin D may naturally protect human reproduction and women undergoing assisted reproduction from Covid-19 risk. J Reprod Immunol. 2021;144:103271.

8. Frenzel A, Hust M, Schirrmann T. Expression of recombinant antibodies. Front Immunol. 2013;4:217.

9. Harmsen M, De Haard H. Properties, production, and applications of camelid single-domain antibody fragments. Appl Microbiol Biotechnol. 2007;77(1):13-22.

10. Hoffmann M, Kleine-Weber H, Krüger N, Mueller MA, Drosten C, Pöhlmann S. The novel coronavirus 2019 (2019-nCoV) uses the SARS-coronavirus receptor ACE2 and the cellular protease TMPRSS2 for entry into target cells. BioRxiv. 2020.

11. Imai Y, Kuba K, Rao S, Huan Y, Guo F, Guan B, Yang P, Sarao $\mathrm{R}$, Wada $\mathrm{T}$, Leong-Poi $\mathrm{H}$. Angiotensin-converting enzyme 2 protects from severe acute lung failure. Nature. 2005;436(7047):112-6.

12. Kaur H, Shekhar N, Sharma S, Sarma P, Prakash A, Medhi B. Ivermectin as a potential drug for treatment of COVID-19: an insync review with clinical and computational attributes. Pharmacol Rep. 2021;73:1-14.

13. Khalili JS, Zhu H, Mak NSA, Yan Y, Zhu Y. Novel coronavirus treatment with ribavirin: groundwork for an evaluation concerning COVID-19. J Med Virol. 2020;92(7):740-6.

14. Khan FA, Stewart I, Fabbri L, Moss S, Robinson K, Smyth AR, Jenkins G. Systematic review and meta-analysis of anakinra, sarilumab, siltuximab and tocilizumab for COVID-19. Thorax. 2021 Feb 12: thoraxjnl-2020-215266.

15. Kraft CS, Hewlett AL, Koepsell S, Winkler AM, Kratochvil CJ, Larson L, Varkey JB, Mehta AK, Lyon GM III, Friedman-Moraco RJ. The use of TKM-100802 and convalescent plasma in 2 patients with Ebola virus disease in the United States. Clin Infect Dis. 2015;61(4):496-502.

16. Ksiazek TG, Erdman D, Goldsmith CS, Zaki SR, Peret T, Emery S, Tong S, Urbani C, Comer JA, Lim W. A novel coronavirus associated with severe acute respiratory syndrome. N Engl J Med. 2003;348(20):1953-66.

17. Kumar V, Kancharla S, Jena MK. In silico virtual screeningbased study of nutraceuticals predicts the therapeutic potentials of folic acid and its derivatives against COVID-19. Virusdisease. 2021;32(1):1-9. 
18. Liu J, Zheng X, Huang Y, Shan H, Huang J. Successful use of methylprednisolone for treating severe COVID-19. J Allergy Clin Immunol. 2020;146(2):325-7.

19. Rabi FA, Al Zoubi MS, Kasasbeh GA, Salameh DM, Al-Nasser AD. SARS-CoV-2 and coronavirus disease 2019: what we know so far. Pathogens. 2020;9(3):231.

20. Schlesinger N, Firestein BL, Brunetti L. Colchicine in COVID19: an old drug, new use. Curr Pharmacol Rep. 2020;6(4):137-45.

21. Snijder EJ, Van Der Meer Y, Zevenhoven-Dobbe J, Onderwater JJ, Van Der Meulen J, Koerten HK, Mommaas AM. Ultrastructure and origin of membrane vesicles associated with the severe acute respiratory syndrome coronavirus replication complex. J Virol. 2006;80(12):5927-40.

22. Tortorici MA, Veesler D. Structural insights into coronavirus entry. Adv Virus Res. 2019;105:93-116.

23. Walker LM, Burton DR. Passive immunotherapy of viral infections:'super-antibodies' enter the fray. Nat Rev Immunol. 2018;18(5):297.

24. Wan Y, Shang J, Graham R, Baric RS, Li F. Receptor recognition by the novel coronavirus from Wuhan: an analysis based on decade-long structural studies of SARS coronavirus. J Virol. 2020. https://doi.org/10.1128/JVI.00127-20.
25. Wang M, Cao R, Zhang L, Yang X, Liu J, Xu M, Shi Z, Hu Z, Zhong W, Xiao G. Remdesivir and chloroquine effectively inhibit the recently emerged novel coronavirus $(2019-\mathrm{nCoV})$ in vitro. Cell Res. 2020;30(3):269-71.

26. Wong SK, Li W, Moore MJ, Choe H, Farzan M. A 193-amino acid fragment of the SARS coronavirus $\mathrm{S}$ protein efficiently binds angiotensin-converting enzyme 2. J Biol Chem. 2004;279(5):3197-201.

27. Wrapp D, Wang N, Corbett KS, Goldsmith JA, Hsieh C-L, Abiona O, Graham BS, McLellan JS. Cryo-EM structure of the 2019-nCoV spike in the prefusion conformation. Science. 2020;367(6483):1260-1263.

28. Wu A, Peng Y, Huang B, Ding X, Wang X, Niu P, Meng J, Zhu Z, Zhang Z, Wang J. Genome composition and divergence of the novel coronavirus (2019-nCoV) originating in China. Cell Host Microbe. 2020;27(3):325-8.

Publisher's Note Springer Nature remains neutral with regard to jurisdictional claims in published maps and institutional affiliations. 